\title{
Liver diseases and pregnancy
}

\author{
Pietro Crispino, ${ }^{1}$ Luca Fontanella, ${ }^{2}$ Paola Gnerre ${ }^{3}$ \\ ${ }^{1}$ Unit of Gastroenterology and Digestive Endoscopy, Sandro Pertini Hospital, Roma; ${ }^{2}$ Unit of Internal Medicine, Ospedale del \\ Buon Consiglio Fatebenefratelli, Napoli; ${ }^{3}$ Unit of Internal Medicine, San Paolo Hospital, Savona, Italy
}

\begin{abstract}
Pregnancy is a time of great maternal physiological and metabolic changes and affects biochemical and hematological parameters used in the assessment of liver disease. Due to the increased physiological and metabolic stress of pregnancy, liver disorders that have previously been subclinical may become symptomatic such as cholestatic diseases. The viral hepatitis constitutes a huge disease burden worldwide and the pregnant state confers particular concerns for the mother and her baby. In particular, hepatitis $\mathrm{E}$ has a predilection for the pregnant population and confers a particularly poor prognosis. In addition, certain pregnancy specific disorders such as elevated liver enzymes, low platelets syndrome, acute fatty liver of pregnancy, and obstetric cholestasis-affect primarily the liver. It is important to know how to diagnose and manage these conditions and distinguish them from non-pregnancy specific conditions as this will change the timing and management of affected women and their babies, some of whom can be seriously ill.
\end{abstract}

\section{Physiological changes in liver during preg- nancy}

The pregnant woman experiences physiological changes to support fetal growth and development. The levels of estrogens (estradiol) and progesterone increase progressively during pregnancy. These sex hormones have effects on hepatic metabolic, synthesis, and excretory functions. The phenomenon of hemodilution secondary to the increase in plasma volume and the increases in cardiac output, decreases the serum protein concentrations. ${ }^{1}$ Liver, in course of pregnancy, reveals no specific structural changes. In spite of this, several changes in values of liver function tests occur

Correspondence: Paola Gnerre, Unit of Internal Medicine, San Paolo Hospital, via Genova 30, 17100 Savona, Italy. Tel.: +30.019.8404082.

E-mail: pgnerre@yahoo.it

Key words: Pregnancy; liver disease; metabolic disease.

Conflict of interest: the authors declare no potential conflict of interest.

Received for publication: 25 November 2016.

Revision received: 27 January 2017.

Accepted for publication: 11 February 2017.

This work is licensed under a Creative Commons Attribution NonCommercial 4.0 License (CC BY-NC 4.0).

(C) Copyright P. Crispino et al., 2017

Licensee PAGEPress, Italy

Italian Journal of Medicine 2017; 11:278-287

doi:10.4081/itjm.2017.817 during normal pregnancy. Blood flow to the liver remains unchanged, but the percentage of cardiac output to the liver is reduced, which may impair clearance of substances requiring extensive hepatic metabolism. ${ }^{1}$ Moreover, in pregnancy, gallbladder motility is also decreased for several causes: gallbladder enlargement and incomplete evacuation of bile, increased gallbladder volume during fasting is due to a combination of decreased water absorption by the gallbladder mucosa, enhanced of secretion of cholecystokinin in the response to food intake. All these phenomena can originate to from the high concentration of progesterone. ${ }^{2}$ In this paper, we review the liver-related clinical and pathology changes that occur during pregnancy, subdividing these conditions into: i) conditions associated with pregnant status; ii) conditions complicating the pregnancy; iii) liver conditions present at the beginning of pregnancy.

\section{Conditions associated with pregnant status}

\section{Intrahepatic cholestasis}

Intrahepatic cholestasis of pregnancy (ICP) usually occurs during the last trimester and has a rapid postnatal resolution. ${ }^{3}$ It is characterized by severe pruritus, associated with increase in serum bile acid and aminotransferases (Table 1). The symptoms and biochemical abnormalities resolve rapidly after delivery but may recur in subsequent pregnancies and with the use of hormonal contraception. ${ }^{4}$ Genetic variations may implicate heterozygous or homozygous mutations located in different positions of the genes. All the association studies with these candidate genes stress the complex variability of genotypes, the different 
penetrance, and the influence of several environmental factors. A recent study demonstrated the presence of up-regulation of GABRA2 receptor gene (that codes for a subunit of the gamma-aminobutyric acid type A receptor) is potentially correlated to ICP and in particular, GABA may play a role in the pathogenesis of pruritus in this condition. ${ }^{5}$ Severe ICP (with serum bile acids $>40 \mu \mathrm{mol} / \mathrm{L}$ ) is associated with adverse pregnancy outcome. ${ }^{6}$ The current medical treatment for ICP is ursodeoxycholic acid (UDCA), which acts as several mechanisms of action: protection of hepatocytes and cholangiocytes by replacing endogenous, cytotoxic bile salts, induction of expression of functional transporters at transcriptional and post-transcriptional level, and enhancing bile flow. ${ }^{7,8}$

\section{Eclampsia and preeclampsia}

Pre-eclampsia is a condition that occurs after 20 weeks of pregnancy and/or within 24-48 $\mathrm{h}$ after delivery. It affects $5-10 \%$ of all pregnancies and can involve the kidney, the liver, the central nervous and hematological system. Pre-eclampsia is characterized by hypertension and proteinuria (greater than $300 \mathrm{mg}$ in $24 \mathrm{~h}$ ), right upper quadrant pain, headache, nausea and vomiting. Presence of seizures differentiates eclampsia from pre-eclampsia. ${ }^{9}$ Abnormal liver tests, secondary to vasoconstriction of the hepatic vascular bed, occur in $20-30 \%$ of patients and include 10-to20 -fold elevation in aminotransferases, elevations in alkaline phosphatase and bilirubin increase of less than $5 \mathrm{mg} / \mathrm{dL}^{10}$ (Table 1). Risk factors include extreme maternal age ( $<16$ years and $>45$ years), primiparity, pre-existing hypertension, family history and occurrence in a previous pregnancy. The pathophysiology involves suboptimal utero-placental perfusion associated with systemic inflammatory response and vascular endothelial dysfunction. Genetic predisposition and imbalance of prostacyclin and thromboxane have also been implicated in the pathogenesis of this disturbance. ${ }^{11}$ Pre-eclampsia and eclampsia are associated with 3-to-25-fold increased risk of pulmonary edemas, abruption, aspiration pneumonia, renal failure, hepatic failure, disseminated intravascular coagulation (DIC), and stroke. Hemorrhagic stroke is the most common cause of death, vascular disease, renal, and neurological sequelae. Treatment is aimed to keep the systolic blood pressure below $150 \mathrm{mmHg}$ and the diastolic between 80 and $100 \mathrm{mmHg}$. First line of hypertension treatment in pregnant women with preeclampsia is labetolol, methyldopa or nifedipine. Magnesium sulfate remains the drug of choice for seizure prophylaxis in severe preeclampsia and for controlling seizures in eclampsia. Treatment consists in early delivery whenever possible. ${ }^{12,13}$

\section{Hemolysis, elevated liver enzymes, and low platelets syndrome}

The hemolysis, elevated liver enzymes, and low platelets (HELLP) syndrome is associated with endothelial cell injury and microangiopathic platelet activation and consumption. It occurs in $4-20 \%$ cases of pre-eclampsia. ${ }^{14}$ The disorder can be diagnosed antepartum (in $70 \%$ of cases between 27 and 30 weeks) or postpartum. Risk factors are advanced maternal age, multiparity and Caucasian ethnicity. The pathophysiology remains unknown: activation endothelial cells may lead to release of Von Willebrand factor multimers which are highly reactive with platelets. The syndrome seems to be the final manifestation of some insult that leads to microvascular endothelial damage and intravascular platelet activation. ${ }^{15,16}$ Patients may present with right upper quadrant and epigastric pain, nausea, vomiting, and malaise. Hypertension and proteinuria are ev-

Table 1. Conditions associated with pregnant status.

\begin{tabular}{|c|c|c|}
\hline Conditions associated with pregnant status & Biochemical modifications and clinical manifestation & Period of pregnancy \\
\hline Intrahepatic cholestasis & $\begin{array}{l}\text { It is characterized by severe pruritus, associated with } \\
\text { increase in serum bile acid and aminotransferases }\end{array}$ & Last trimester \\
\hline Eclampsia and preeclampsia & $\begin{array}{l}\text { Pre-eclampsia is characterized by hypertension and } \\
\text { proteinuria (greater than } 300 \mathrm{mg} \text { in } 24 \mathrm{~h} \text { ), right upper } \\
\text { quadrant pain, headache, nausea and vomiting. Presence } \\
\text { of seizures differentiates eclampsia from pre-eclampsia. } \\
\text { Abnormal liver tests include } 10 \text {-to- } 20 \text {-fold elevation in } \\
\text { aminotransferases, elevations in alkaline phosphatase } \\
\text { and bilirubin increase of less than } 5 \mathrm{mg} / \mathrm{dL}\end{array}$ & $\begin{array}{l}\text { After } 20 \text { weeks of pregnancy } \\
\text { and/or within } 24-48 \mathrm{~h} \text { after } \\
\text { delivery }\end{array}$ \\
\hline $\begin{array}{l}\text { Hemolysis, elevated liver enzymes, } \\
\text { and low platelets syndrome }\end{array}$ & $\begin{array}{l}\text { Biochemical findings include elevated aminotransferases } \\
\text { levels (from mild elevation to } 1000 \mathrm{IU} / \mathrm{L} \text {, usually } 300-500 \text { ), } \\
\text { elevated bilirubin (frequently }>5 \mathrm{mg} / \mathrm{dL} \text { ), leukocytosis, } \\
\text { anemia, thrombocytopenia and hypoalbuminemia, increased } \\
\text { uric acid, renal impairment, metabolic acidosis, } \\
\text { hyperammonemia, biochemical pancreatitis }\end{array}$ & $\begin{array}{l}\text { It can occur antepartum } \\
\text { between } 27 \text { and } 30 \text { week) } \\
\text { or postpartum }\end{array}$ \\
\hline
\end{tabular}


ident in up to $85 \%$ of cases. Because of the hemolysis, high serum unconjugated bilirubin and lactate dehydrogenase are frequent. ${ }^{17,18}$ Complications include DIC, pulmonary edema and placental abruption. Perinatal mortality rate is $6-70 \%$, while maternal mortality is $1 \% .{ }^{19}$ Once HELLP develops, the only definitive treatment is delivery. As in pre-eclampsia, breast-feeding is not contraindicated in HELLP syndrome and for women receiving antihypertensive therapy; nifedipine, labetalol, atenolol, methyldopa, captopril and enalapril have shown to be safe. ${ }^{20}$

Acute fatty liver of pregnancy (AFLP) is a microvesicular fatty infiltration of hepatocytes and a common cause of liver failure in pregnancy. It is a late-gestational complication, often occurring at week 28-40. It is a rare disorder affecting from $1: 7000$ to $1: 16,000$ pregnancies, but it is a medical and obstetrics emergency. ${ }^{21}$ Risk factors are nulliparity, preeclampsia, multiple gestation, pregnancies with a male fetus, low body mass index (BMI). ${ }^{22}$ The etiology is unknown. Defects in intra-mitochondrial fatty acid $\beta$-oxidation (enzymatic mutations), in particular a homozygous fetal deficiency of the enzyme long-chain 3-hydroxyacyl-CoA dehydrogenase (LCHAD) in a mother carrying a heterozygous LCHAD deficiency can be found. ${ }^{22}$ However, AFLP may occur in the absence of known genetic mutations. ${ }^{23}$ The initial manifestations of AFLP include headache, fatigue, nausea and vomiting. Clinical presentation may vary from abdominal pain, jaundice, signs of preeclampsia (50\%), hypoglycemia, hepatic encephalopathy, coagulopathy (DIC). Biochemical findings include elevated aminotransferases levels (from mild elevation to $1000 \mathrm{IU} / \mathrm{L}$, usually 300-500), elevated bilirubin (frequently $>5$ $\mathrm{mg} / \mathrm{dL}$ ), leukocytosis, anemia, thrombocytopenia and hypoalbuminemia, increased uric acid, renal impairment, metabolic acidosis, hyperammonemia, biochemical pancreatitis (Table 1). ${ }^{3,9,14}$ The diagnosis is based on clinical and laboratory findings. Liver biopsy is the gold standard although rarely necessary. ${ }^{24}$ Maternal mortality ranges from $7 \%$ to $18 \%$ and fetal mortality from $9 \%$ to $23 \%{ }^{25-27}$ The management of AFLP requires supportive therapy (diet low in fat and protein and high in carbohydrates, blood components, plasma exchange and hemodialysis, broad-spectrum antibiotics, correction of dehydration, electrolyte and acid-base balance, treatments to protect the liver, reduce jaundice, and diminish liver enzymes); rapid delivery: if vaginal delivery cannot be achieved quickly, Cesarean section is the preferred method. ${ }^{25,27}$ Breast-feeding is not contraindicated by AFLP itself, however this should be evaluated on the basis of the supportive therapy needed for maternal stabilization in the intensive care setting.

\section{Liver disease occurring during pregnancy}

\section{Acute viral hepatitis}

The most common cause of jaundice in pregnancy is acute viral hepatitis. The incidence of hepatitis in pregnancy varies greatly throughout the world according to hygiene, sanitation and socioeconomic conditions. ${ }^{28}$

Hepatitis A virus (HAV) is the most common cause of acute viral hepatitis in the general population but its occurrence during pregnancy has been scarcely reported. Hepatitis A is not associated with a severe outcome during pregnancy and vertical transmission is very rare. HAV vaccination should be considered particularly for women living in areas of high endemicity and poor socioeconomic conditions, to avoid maternal and fetal complications associated with HAV infection in pregnancy. Since there is no evidence of HAV vertical transmission with lactation, breast-feeding appears to be safe.

Acute hepatitis B virus (HBV) infection is not associated with an increased mortality or congenital malformations, although it can cause spontaneous abortion in the first weeks of pregnancy.$^{29}$ No difference in mortality or occurrence of fulminant hepatitis was found between the pregnant or not pregnant women. Clinical recovery was also similar between pregnant and non-pregnant women. However, significantly higher levels of hepatitis B surface antigen (HBsAg) and lower ant-HBs seroconversion rates were found in pregnant patients than in non-pregnant patients, indicating that pregnancy could be a risk factor for chronicity following acute HBV infection. Acute HBV infection in pregnancy has a higher rate of vertical transmission than that usually occurring during delivery, due to newborn exposure to cervical secretions and maternal blood. ${ }^{30} \mathrm{HBV}$ vaccination and hepatitis B immune globulin administration to newborns of HBsAg-positive mothers represent the main strategy to prevent $\mathrm{HBV}$ vertical transmission. ${ }^{31}$

Acute hepatitis $\mathrm{C}$ virus (HCV) infection has been rarely reported during pregnancy and is limited to high-risk groups, such as intravenous drug users. Frequency of acute hepatitis $\mathrm{C}$ during pregnancy is estimated between $0.4 \%$ and $6 \% .{ }^{32} \mathrm{HCV}$ infection can be vertically transmitted (risk from $3 \%$ to $5 \%$ ), but there is no evidence of increased transmission through breast-feeding. ${ }^{33}$ However antiviral treatment is contraindicated due to the teratogenic effect of drugs available until recently ${ }^{34}$ while no data are available for the new interferon-free regimens in this setting.

Hepatitis D virus (HDV) can be acquired by co-infection with HBV or by super-infection of a HBV carrier. ${ }^{35}$ Data regarding acute hepatitis $\mathrm{D}$ and pregnancy are scant. Considering the availability of HBV vaccination and the change in HDV epidemiology, acute hepatitis D in pregnancy appears to be only sporadic. 
Hepatitis E virus (HEV) is responsible for major outbreaks of acute hepatitis in developing countries. $\mathrm{HEV}$ is enterally transmitted and clinical manifestations are similar to other forms of viral hepatitis, except in pregnant women that are at greater risk of developing fulminant hepatitis ( $25 \%$ mortality rate) ${ }^{36}$ Authors found that fulminant hepatic failure was more common and maternal mortality was greater in HEVinfected women than in non-HEV-infected women. Moreover, women with HEV infection had a higher risk of intrauterine fetal death. ${ }^{37}$ Vertical transmission rates are reported between $33.3 \%$ and $78.9 \% .^{38,39}$ There is currently no evidence of HEV transmission through breast-milk.

\section{Gallstone disease}

Gallstones are common during pregnancy. The prevalence ranges between $2.5 \%$ and $11 \%$ of cases. ${ }^{32}$ During pregnancy, female sex hormones are endogenously increased, and biliary sludge (composed of cholesterol, calcium bilirubinate and mucin) appears in $5-30 \%$ of women. ${ }^{40}$ In the post-partum period sludge resolution develops in two-third of cases, small gallstones (microlithiasis) disappear in one-third, but definite gallstones become established in approximately $5 \%$ of cases. ${ }^{41,42}$ Additional risk factors include obesity, reduced high-density lipoprotein cholesterol and metabolic syndrome. ${ }^{40}$ Acute biliary colic or uncomplicated cholecystitis can be treated conservatively but endoscopic retrograde cholangiopancreatography and laparoscopic cholecystectomy should be considered in cases of multiple relapse of the disease. ${ }^{43}$ The use of drugs such as UDCA and the lipid-lowering compound ezetimibe could also be considered. ${ }^{44}$ Cholecystectomy during pregnancy is not entirely safe because of the abortion risk with anesthesia and for this reason, laparoscopic cholecystectomy, when indicated, should be performed in the second trimester to avoid serious complications.

\section{Vascular liver diseases}

In pregnancy, the levels of coagulation factors VII and VIII, von Willebrand factor and fibrinogen are increased, while free protein S levels are reduced. Moreover, increased plasminogen activator inhibitor- 1 and 2 (the latter synthesized by the placenta) decrease fibrinolytic activity. Such changes shift the hemostatic balance towards hypercoagulability, which persists up to 8 weeks after delivery. ${ }^{45}$ Therefore, vascular liver diseases, can occur and worsen the normal course of pregnancy.

\section{Budd-Chiari syndrome}

Budd-Chiari syndrome (BCS) is a rare disease caused by the obstruction of the hepatic venous outflow, due to thrombosis of the hepatic veins or of the suprahepatic portion of the inferior vena cava, leading to sinusoidal congestion, ischemic liver damage and portal hypertension. ${ }^{46,47}$ One or more risk factors for venous thromboembolism are usually present in BCS patients. Pregnancy, as well as oral contraception or estrogen-replacement therapy, may precipitate BCS. ${ }^{48-52} \mathrm{BCS}$ occurring in pregnancy accounts for about $15 \%$ of all women with BCS..$^{53}$ Symptoms include fever, abdominal pain, ascites, lower limb edema, jaundice, gastrointestinal bleeding and hepatic encephalopathy. In pregnancy, the clinical presentation is frequently fulminant, with a high mortality. Ultrasound is the imaging technique of choice in pregnancy as there is no ionizing radiation exposure associated with it. ${ }^{54}$ The safety of gadolinium-based contrast agents is controversial; therefore, magnetic resonance imaging should be used if the diagnosis of BCS cannot be otherwise excluded. The management of BCS occurring in pregnancy differs from that in non-pregnant women as vitamin $\mathrm{K}$ antagonists (VKA) are contraindicated due to risk of fetal hemorrhage and teratogenicity. ${ }^{54} \mathrm{~A}$ stepwise treatment, starting with a twice-daily low molecular weight heparin $(\mathrm{LMWH})$, followed by transjugular intrahepatic portosystemic shunt (TIPS) in failures or relapses, is recommended. Liver transplantation is possible. ${ }^{55} \mathrm{An}-$ ticoagulation, with LMWH or VKA, can be restarted $12 \mathrm{~h}$ after delivery (or $24 \mathrm{~h}$ after Cesarean section). Breast-feeding is contraindicated in women taking LMWH, but not in those taking VKA, which are excreted inactive in maternal milk (Class I, Level C).

\section{Acute extra hepatic portal vein obstruction}

Acute extra hepatic portal vein obstruction (EHPVO) is the sudden, usually thrombotic, occlusion of the portal vein, variably involving its intrahepatic branches or tributaries, mesenteric and splenic veins. Thrombophilia and abdominal precipitating factors often coexist. Acute EHPVO often presents with abdominal pain, ascites or fever. As for BCS, Doppler ultrasound is the procedure of choice in pregnancy. In acute EHPVO not occurring in pregnancy, if early recognized and treated, a $75 \%$ rate of complete or partial recanalization is expected. ${ }^{56}$ As in non-pregnant women, the treatment is based on anticoagulation with LMWH. Anticoagulation can be restarted $12 \mathrm{~h}$ after delivery (or $24 \mathrm{~h}$ after Cesarean section) with VKA if breast-feeding is desired.

\section{Pregnancy in patients with pre-existing chronic liver disease}

\section{Chronic viral hepatitis}

In women with chronic HBV infection, immunological changes typical of pregnancy may cause an in- 
crease in HBV DNA levels while alanine aminotransferase (ALT) remain normal or near normal. Mild exacerbations may occur after delivery. ${ }^{57,58}$ In clinical practice, women who are HBV-positive carriers should be counselled regarding pregnancy both on and off treatment. In all cases, indication to treatment according to current recommendations should be considered and discussed with the patient. ${ }^{59}$ When fibrosis is mild or absent, treatment can be delayed; stopping antiviral drugs may be considered in women currently receiving treatment. Pegylated interferon (PEG-IFN) is contraindicated during pregnancy. When treatment is indicated, tenofovir is the drug of choice (see below); women who become pregnant while receiving entecavir, adefovir or PEG-IFN, should be switched to tenofovir, if treatment is indicated. Vertical transmission of $\mathrm{HBV}$ infection is prevented by vaccine and anti-HBs immunoglobulin administration to newborns within $12 \mathrm{~h}$ after delivery. ${ }^{60} \mathrm{~A}$ long-term follow-up of babies born to mothers treated with telbivudine confirmed safety. ${ }^{61}$ Lamivudine given from week 32 of pregnancy to mothers with serum HBV DNA $\geq 109$ $\mathrm{IU} / \mathrm{mL}$ reduced the incidence of newborn infection in a placebo-controlled trial; ${ }^{62}$ however not all newborns received complete prophylaxis.

Hepatitis $\mathrm{C}$ is a major public health problem: worldwide more than 200 million people are infected with $\mathrm{HCV}$, with an overall prevalence of $3.3 \%$. The epidemiology of $\mathrm{HCV}$ varies among countries and its prevalence in pregnant women has not been extensively studied. The prevalence of anti-HCV positivity among pregnant women in Europe is estimated between 1.7\% and $2.5 \%, 32,63,64$ but increases to $8 \%$ in some developing countries. The natural history of liver disease in pregnant women and their offspring is not fully understood. Pregnancy does not seem to modify the natural course of HCV disease: pregnant women are generally asymptomatic and during pregnancy a significant reduction in ALT levels has been reported, with a rebound during the postpartum period, accompanied by HCV RNA increase towards the end of pregnancy in the majority of $\mathrm{HCV}$-infected pregnant women. Preliminary data suggest no increase in spontaneous miscarriage rate or in obstetric complications in HCV-infected women compared to controls. However, some studies reported a decrease in newborn weight, an increase in congenital abnormalities and in preterm delivery rate. ${ }^{65,66}$ Moreover, retrospective data suggest a significantly higher incidence of intrahepatic cholestasis of pregnancy in $\mathrm{HCV}$-infected pregnant women compared with controls. Chronic hepatitis $\mathrm{C}$ can lead to vertical transmission of $\mathrm{HCV}$, while it only marginally influences the course of pregnancy and seldom induces spontaneous abortion. The global rate of vertical transmission of $\mathrm{HCV}$ is relatively low; it has been estimated between $3 \%$ and $5 \%,{ }^{67}$ in infants born from HCV-positive moth- ers. Delivery modalities do not influence transmission, and Cesarean section does not decrease perinatal $\mathrm{HCV}$ transmission. Breast-feeding should not be discouraged, as transmission of $\mathrm{HCV}$ by breast-feeding has not been demonstrated. ${ }^{68}$ Antiviral therapy for $\mathrm{HCV}$ is contraindicated during pregnancy due to the potential teratogenic effects of ribavirin and the side effects of PEG-IFN. No data are available regarding new interferon-free regimens. Treatment options should be offered before pregnancy. ${ }^{69,70}$

\section{Autoimmune hepatitis}

Autoimmune hepatitis (AIH) usually affects women in fertile age, thus pregnancy is rather common in those patients. The presence of maternal cirrhosis impacted on fetal outcome, and the live birth rate was lower in mothers with liver cirrhosis at the time of conception $(\mathrm{P}=0.002)$. The maternal course is highly variable. In case of pregnancy occurring at presentation of AIH with acute onset, liver disease may have a fulminant course and the fetus has a low chance of survival. ${ }^{71}$ In general, women who reach disease remission and do not have cirrhosis with portal hypertension, have a high chance of a favorable pregnancy outcome. ${ }^{72}$ In general, pregnancy confers a beneficial effect on immunosuppression with a reduction in maintenance therapy. This is due to several factors, including the physiological increase of serum cortisol. ${ }^{73,74}$ In clinical practice the dosage of steroids to maintain remission should be reduced in case of pregnancy. However, pregnancy-related flares may occur in up to $21 \%$ of cases, whereas the probability of fares is higher after delivery with an incidence as high as $40 \%{ }^{75}$

\section{Primary biliary cholangitis}

Primary biliary cholangitis (PBC) generally develops near menopausal age, with a broad range that includes both the fertile and the geriatric ages. Pregnancies are rather uncommon after PBC has been diagnosed, and there are limited reports in the literature specifically focusing on the outcome of pregnancy in PBC patients, as well as on the effect of pregnancy on PBC course. Finally, the outcome of pregnancy and the influence of pregnancy on the course of PBC were analyzed in a case-control study including 186 consecutive patients with PBC who had at least one conception and a 1:2 control group of 367 healthy women. ${ }^{76}$ The two groups' history was similar in terms of miscarriages, voluntary interruption of pregnancy, and term and pre-term deliveries. Pruritus during pregnancy was recorded in 15 pregnancies involving $13 \mathrm{PBC}$ patients (3\%) and in none of controls. Perinatal and postnatal deaths and complications at childbirth were only recorded in the PBC patients, in- 
volving 11 babies $(2.7 \%, \mathrm{P}<0.05)$. Eight pregnancies occurred after $\mathrm{PBC}$ was diagnosed in 6 patients, all of whom had a favorable course at term, with no complications at childbirth. UDCA is safe and well tolerated during pregnancy. UDCA treatment with increasing doses up to $25 \mathrm{mg} / \mathrm{kg} /$ day during breastfeeding has shown to be safe, and no adverse effects were observed in either infants or mothers. ${ }^{77}$

\section{Primary sclerosing cholangitis}

Primary sclerosing cholangitis (PSC) has an incidence around $0.9-1.3$ per 100,000 per year and a prevalence around 8.5-14.2 per 100,000 in Northern Europe and in the United States. ${ }^{78}$ Up to $80 \%$ of PSC patients have concurrent inflammatory bowel disease (IBD).$^{78}$ Fertility does not seem to be reduced in patients with PSC, and in young female patients, pregnancy is possible. No strong association has been found between the development of PSC and previous perinatal events including birth length, breast-feeding and the majority of maternal medical complications. ${ }^{79}$ Continuation of treatment with UDCA or azathioprine had no negative effects on pregnancy outcome. The exacerbation of IBD during pregnancies complicated by PSC is described in $25-30 \%$ of cases. ${ }^{80}$ PSC also carries a risk of biliary sludge and stones; nevertheless, the risk of biliary colic and/or complications of gallstones is very low.

\section{Hemochromatosis}

Hemochromatosis $(\mathrm{HH})$ is a recessive disease (prevalence 2-5/1000) due in most cases to homozygosity for the $\mathrm{C} 282 \mathrm{Y}$ mutation of $H F E$ gene, which confers a genetic predisposition to progressive body iron overload. Host-related and acquired factors are needed for the phenotypic expression of the disease. Fertility is impaired only if diagnosis and treatment are late, when women have developed gonadal dysfunction. Given the recessive pattern of inheritance, there is no need for prenatal diagnosis for pregnant women with $\mathrm{HH} .{ }^{81}$ Iron should not be prescribed routinely to pregnant women with $\mathrm{HH}$ unless clearly iron deficient, and ferritin should be frequently checked. In the presence of iron overload, iron depletion by phlebotomy or chelators should be delayed to the end of pregnancy, unless evident cardiac involvement is present. Gestational diabetes seems to be more frequent in pregnant women heterozygous for the $\mathrm{C} 282 \mathrm{Y}$ mutation. $^{82}$

\section{Wilson's disease}

Wilson's disease is a recessive disease (prevalence $1 / 30,000$ ) characterized by defective biliary excretion of copper and consequent accumulation in liver and brain, due to rare mutations of $A T P 7 B$ gene, which en- codes a copper transporting protein. Clinical presentation, which can occur at any age, may be very different including acute and chronic liver disease, cirrhosis, neuropsychiatric disorders, and acute hemolysis. Women are frequently non-ovulatory, but treatment can restore fertility when started in an early stage of the disease. Successful treatment allows pregnancy but copper status should be optimized before pregnancy. Likelihood of delivering a homozygote, without knowledge of the paternal status, is $0.05 \% .{ }^{83}$ Maintaining therapy during pregnancy is essential because interrupting the drugs has been associated with hemolytic episodes, hepatic insufficiency and maternal death. d-Penicillamine is safe, although the drug is teratogenic in animal studies, and there are reports of neonates with cutaneous abnormalities. In patients on D-penicillamine therapy, the dose should be reduced by $25-50 \%$ of the pre-pregnancy dose to reduce fetal risks.

\section{Porphyria}

Porphyria can present as acute or chronic disease. The inheritance pattern is usually autosomal dominant, with low penetrance, and trigger factors are needed for the disease to become apparent. Acute porphyria usually manifests after puberty, more frequently in women with a peak in the third decade. ${ }^{84}$ Attacks occur particularly during periods of hormonal change (e.g., luteal phase of the menstrual cycle, and during oral contraceptive use). Pregnancy is not contraindicated, although attacks are more frequent during early weeks of gestation, potentially causing maternal and fetal problems, and in the immediate postpartum period. Recurrent attacks may occur during pregnancy in patients with acute intermittent porphyria, variegate porphyria, or hereditary coproporphyria. Porphyria cutanea tarda may present for the first time during pregnancy. In a population-based study, pregnant women with the heritable form of porphyria cutanea tarda or with active acute porphyria had a significant excess risk of prenatal death, low birth weight and premature delivery ${ }^{84}$ Most commonly no specific therapy for acute porphyria is required during pregnancy. In case of acute attacks, standard therapy with glucose infusion (200-500 g/day) and heme arginate (4 mg/kg/day) is recommended for 3-4 days.

\section{Alcoholic liver disease}

Pregnancy in alcoholic liver disease (ALD) presents two main problems: liver damage and alcohol intake, including the effects of alcohol on other organs and alcohol dependence, itself. ${ }^{85}$ ALD comprises a large spectrum of alcohol-related liver diseases, ranging from fatty liver or simple steatosis to alcoholic hepatitis, chronic hepatitis with hepatic fibrosis or cir- 
rhosis. Pregnancy data are scarce in women with ALD, as women with ALD are often infertile. ALD leads to anovulation and amenorrhea due to many factors including disturbed estrogen and endocrine metabolism. ${ }^{86}$ When pregnancy is successful in a cirrhotic woman, spontaneous abortion rate, risk of prematurity, and perinatal death rate are all increased.$^{87}$ Alcoholic cirrhotic patients have a high risk of liver decompensation because of worsening synthetic liver function, development of ascites, and hepatic encephalopathy with high maternal mortality. ${ }^{87,88}$ Maternal prognosis depends on the degree of hepatic dysfunction during pregnancy rather than its cause. ${ }^{89}$ Portal hypertension worsens during pregnancy because of increased blood volume and flow. Portal pressures can also increase because of an increased vascular resistance due to external compression of the inferior vena cava by the gravid uterus. All patients with cirrhosis should undergo variceal screening. Banding before pregnancy, although not proven, is appropriate for high-risk varices (moderate evidence; weakly positive recommendation). Finally, although there are no good studies evaluating the impact of vaginal delivery on the risk of variceal bleeding, it is recommended that patients have Cesarean section to avoid increased straining. ${ }^{90}$ Abusive and heavy drinking are associated with fetal alcohol syndrome (FAS), which includes growth retardation, central nervous system damage, neurodevelopmental delays and facial malformations. ${ }^{91}$ Epilepsy is often reported in children with FAS. ${ }^{92}$ Even in the absence of FAS, heavy alcohol consumption during pregnancy is correlated with adverse outcomes, including miscarriage, stillbirth, preterm delivery and small-for-gestational age (SGA) birth. ${ }^{93}$ Chronic liver disease is associated with increased levels of inflammatory cytokines, which may increase the risk of preterm birth. ${ }^{94}$ A Danish study found that alcohol consumption below four drinks per week did not increase the risk of preterm birth. Several studies have been conducted to investigate whether alcohol intake during breast-feeding can cause damage to the baby. In fact, there was no difference in the scores of cognitive development, while a small but significant difference, was detected in motor development of children. ${ }^{95}$ Benzodiazepines seem the most recommendable option for managing alcohol withdrawal, and psychosocial interventions succeed in reducing alcohol consumption or in maintaining abstinence in alcohol-dependent pregnant women. ${ }^{96}$

\section{Non-alcoholic liver disease}

Non-alcoholic fatty liver disease (NAFLD) is the most common chronic liver disease worldwide. It is the hepatic expression of the metabolic syndrome and shares the risks associated with its components. Further evaluation by liver ultrasound showed a variable degree of fatty liver and confirmed the diagnosis of NAFLD, associated with increased BMI. The presence of NAFLD did not affect the maternal and neonatal outcomes. Pregnancy is associated with a 50-60\% decrease in insulin sensitivity during physiological gestation $^{97}$ and NAFLD is driven by insulin resistance. The duration of the pregnancy-related insulin resistance, albeit very short, could have a clinical impact on NAFLD in susceptible individuals. Although there are no specific studies considering the impact of NAFLD on maternal and fetal outcomes, some data can be inferred from the literature on obese and diabetic pregnant women, given the extremely high prevalence of NAFLD in obesity and type 2 diabetes. Consequently, overweight and obese women are at increased risk of metabolic dysfunctions during pregnancy. Indeed, obese women have a $10-15 \%$ increased risk for preeclampsia ${ }^{98}$ and are at higher risk to develop gestational diabetes mellitus (GDM). ${ }^{99}$ There is now growing evidence that maternal obesity, GDM and the fetal nutritional environment may contribute to the offspring's risk of developing juvenile obesity and metabolic disorders. Moreover, excessive maternal lipid supply in utero, coupled with the reduced oxidative capacity of the fetal liver, can promote hepatic steatosis, mitochondrial dysfunction, oxidative damage and inflammation, perhaps priming the liver to a later development of NAFLD and to its progression to non-alcoholic steatohepatitis. ${ }^{100,101}$ Among the conditions associated with NAFLD, the polycystic ovary syndrome (PCOS) deserves particular attention. PCOS has recently been recognized as a potential risk factor for NAFLD. ${ }^{102}$ Early diagnosis of these two associated conditions, is mandatory to ensure a multidisciplinary approach. Screening has not been recommended.

\section{Cirrhosis and portal hypertension}

Pregnancy is uncommon in women with liver cirrhosis, because they tend to be past childbearing age or infertile due to the condition. Cirrhosis leads to anovulation and amenorrhea because of many factors including disturbed of estrogen and endocrine metabolism. When pregnancy is successful in a cirrhotic woman, spontaneous abortion rate, risk of prematurity, and perinatal death rate are all increased. ${ }^{4}$ Unfortunately, the outcomes and the optimal management of pregnancy with cirrhosis and portal hypertension in the modern era of obstetrics is still undefined. ${ }^{32}$ Portal hypertension worsens during pregnancy because of increased blood volume and flow, and further increased vascular resistance due to external compression of the inferior vena cava by the gravid uterus. Indeed, up to $25 \%$ of patients with varices have a bleeding episode during pregnancy. The greatest risk is seen in the second trimester (when portal pressures peak), and during delivery, because of the repeated use of the Valsalva maneuver during ex- 
pulsion. However, there are no clear recommendation regarding mode of delivery, ${ }^{88,103}$ even if Cesarean section is recommended in patients with large esophageal or gastric varices. Regarding the treatment of variceal bleeding during pregnancy, all cirrhotic patients should undergo variceal screening by upper endoscopy. Banding before pregnancy is appropriate for high-risk varices, although official guidelines are lacking. TIPS can be considered in extreme cases of variceal bleeding, although there is risk of radiation exposure to the fetus. Propranolol has also been used safely in pregnancy. Side effects include fetal growth retardation, neonatal bradycardia and hypoglycemia. Propranolol does not appear to be teratogenic, but maternal and fetal propranolol toxicity may occur. Since data on safety of breastfeeding in cirrhosis are scarce, all medications used during breast-feeding should be checked for infant exposure risk. The outcome of pregnancy in patients with non-cirrhotic portal hypertension $(\mathrm{NCPH})$ is more favorable. Recent studies in women with $\mathrm{NCPH}$ show near normal fertility with comparable incidences of spontaneous abortions and stillbirths. No increase in the incidence of hematemesis during pregnancy has been observed. In this setting, a higher risk of SGA babies has been reported. ${ }^{104}$

\section{References}

1. Moore M, Nelson-Piercy C. Pregnancy and the liver. Br J Hosp Med 2011;72:M170-3.

2. Than NN, Neuberger J. Liver abnormalities in pregnancy. Best practice and research. Clin Gastroenterol 2013;27:565-75

3. Bacq Y, Sentilhes L, Reyes HB, et al. Efficacy of ursodeoxycholic acid in treating intrahepatic cholestasis of pregnancy: a meta-analysis. Gastroenterology 2012;143: 1492-501.

4. Sibai BM. Diagnosis and management of gestational hypertension and preeclampsia. Obstet Gynecol 2003;102: 181-92.

5. Wallis AB, Saftlas AF, Hsia J et al. Secular trends in the rates of preeclampsia, eclampsia, and gestational hypertension, United States, 1987-2004. Am J Hypertens 2008; 21:521-6.

6. National Institute for Health and Care Excellence (NICE). Hypertension in pregnancy: diagnosis and management. Clinical guideline [CG107]; August 2010. Available from: https://www.nice.org.uk/guidance/cg107

7. Ahmed KT, Almashhrawi AA, Rahman RN, et al. Liver diseases in pregnancy: diseases unique to pregnancy. World J Gastroenterol 2013;21:7639-46.

8. Brown CM, Garovic VD. Mechanisms and management of hypertension in pregnant women. Curr Hypertens Rep 2011;13:338-46.

9. Kia L, Rinella ME. Interpretation and management of hepatic abnormalities in pregnancy. Lancet 2010;375: 594-605.

10. Fitzpatrick KE, Hinshaw K, Kurinczuk JJ, et al. Risk factors, management, and outcomes of hemolysis, ele- vated liver enzymes, and low platelets syndrome and elevated liver enzymes, low platelets syndrome. Obstet Gynecol 2014;123:618-27.

11. Abildggard U, Hemidal K. Pathogenesis of the syndrome of hemolysis, elevated liver enzymes, and low platelet count (HELLP): a review. Eur J Obstet Gynecol Reprod Biol 2013;166:117-23.

12. Aloizos S, Seretis C, Liakos N, et al. HELLP syndrome: understanding and management of a pregnancy-specific disease. J Obstet Gynaecol 2013;33:331-7.

13. Bacq Y. Liver diseases unique to pregnancy: a 2010 update. Clin Res Hepatol Gastroenterol 2011;35:182-93.

14. Haram K, Svendsen E, Abildgaard U. The HELLP syndrome: clinical issues and management. A review. BMC Pregn Childb 2009;9:8.

15. Aydin S, Ersan F, Ark C, et al. Partial HELLP syndrome: maternal, perinatal, subsequent pregnancy and longterm maternal outcomes. J Obstet Gynaecol Res 2014; 40:932-40.

16. Magee LA, Pels A, Helewa M, et al. Diagnosis, evaluation, and management of the hypertensive disorders of pregnancy: executive summary. J Obstet Gynaecol Canada 2014;36:416-41.

17. Boregowda G, Shehata HA. Gastrointestinal and liver disease in pregnancy. Best practice and research. Clin Obstet Gynaecol 2013;27:835-53.

18. ACOG Committee on Practice Bulletins - Obstetrics. ACOG practice bulletin. Diagnosis and management of preeclampsia and eclampsia. Number 33, January 2002. Obstet Gynecol 2002;99:159-67.

19. Nelson DB, Yost NP, Cunningham FG. Acute fatty liver of pregnancy: clinical outcomes and expected duration of recovery. Am J Obstet Gynecol 2013;209:456.e1-7.

20. Vigil-de Gracia P, Montufar-Rueda C. Acute fatty liver of pregnancy: diagnosis, treatment, and outcome based on 35 consecutive cases. J Maternal-Fetal Neonat Med 2011;24:1143-6.

21. Zhou G, Zhang X, Ge S. Retrospective analysis of acute fatty liver of pregnancy: twenty-eight cases and discussion of anesthesia. Gynecol Obstet Invest 2013;76:83-9.

22. Wei Q, Zhang L, Liu X. Clinical diagnosis and treatment of acute fatty liver of pregnancy: a literature review and 11 new cases. J Obstet Gynaecol Res 2010;36:751-6.

23. Licata A, Ingrassia D, Serruto A, et al. Clinical course and management of acute and chronic viral hepatitis during pregnancy. J Viral Hepatit 2014 [Epub ahead of print].

24. Cho GJ, Kim YB, Kim SM, et al. Hepatitis A virus infection during pregnancy in Korea: hepatitis A infection on pregnant women. Obstet Gynecol Sci 2013;56:368-74.

25. Pol S, Corouge M, Fontaine H. Hepatitis B virus infection and pregnancy. Clin Res Hepatol Gastroenterol 2011;35:618-22.

26. Zhang S-L, Han X-B, Yue Y-F. Relationship between HBV viremia level of pregnant women and intrauterine infection: neated PCR for detection of HBV DNA. World J Gastroenterol 1998;4:61-3.

27. Hay JE. Liver disease in pregnancy. Hepatology 2008;47:1067-76.

28. Kubo A, Shlager L, Marks AR, et al. Prevention of vertical transmission of hepatitis B: an observational study. Ann Intern Med 2014;160:828-35.

29. Floreani A. Hepatitis C and pregnancy. World J Gastroenterol 2013;19:6714-20. 
30. Pembrey L, Newell ML, Tovo PA, et al. The management of HCV infected pregnant women and their children European paediatric HCV network. J Hepatol 2005;43:515-25.

31. Krajden S, Bishai F, Huang SN, et al. Clinicopathological study of fulminant hepatitis: coinfection with hepatitis B virus and delta agent. CMAJ 1986;135:1282-5.

32. Abravanel F, Lhomme S, Dubois M, et al. Hepatitis E virus. Méd Malad Infect 2013;43:263-70.

33. Patra S, Kumar A, Trivedi SS, et al. Maternal and foetal outcomes in pregnant women with acute hepatitis E virus infection. Ann Intern Med 2007;147:28-33.

34. Khuroo MS, Kamili S, Khuroo MS. Clinical course and duration of viremia in vertically transmitted hepatitis $\mathrm{E}$ virus (HEV) infection in babies born to HEV-infected mothers. J Viral Hepatit 2009; 16:519-23.

35. Stinton LM, Shaffer EA. Epidemiology of gallbladder disease: cholelithiasis and cancer. Gut Liver 2012;6:172-87.

36. Maringhini A, Ciambra M, Baccelliere P, et al. Biliary sludge and gallstones in pregnancy: incidence, risk factors, and natural history. Ann Intern Med 1993;119:116-20.

37. Davit-Spraul A, Gonzales E, Baussan C, et al. The spectrum of liver diseases related to $\mathrm{ABCB} 4$ gene mutations: pathophysiology and clinical aspects. Semin Liver Dis 2010;30:134-46.

38. Othman MO, Stone E, Hashimi M, et al. Conservative management of cholelithiasis and its complications in pregnancy is associated with recurrent symptoms and more emergency department visits. Gastrointest Endosc 2012;76:564-9.

39. De Bari O, Wang TY, Liu M, et al. Cholesterol cholelithiasis in pregnant women: pathogenesis, prevention and treatment. Ann Hepatol 2014;13:728-45.

40. Chan CHY, Enns RA. ERCP in the management of choledocholithiasis in pregnancy. Curr Gastroenterol Rep 2012;14:504-10.

41. Lu EJ, Curet MJ, El-Sayed YY, et al. Medical versus surgical management of biliary tract disease in pregnancy. Am J Surg 2004;188:755-9.

42. James AH. Prevention and management of venous thromboembolism in pregnancy. Am J Med 2007;120:S26-34.

43. Valla DC. The diagnosis and management of the BuddChiari syndrome: consensus and controversies. Hepatology 2003;38:793-803.

44. Mohanty, D., Shetty, S., Ghosh, K. et al. Hereditary thrombophilia as a cause of Budd-Chiari syndrome: a study from Western India. Hepatology 2001;34:666-70.

45. Janssen HL, Meinardi JR, Vleggaar FP, et al. Factor V Leiden mutation, prothrombin gene mutation, and deficiencies in coagulation inhibitors associated with BuddChiari syndrome and portal vein thrombosis: results of a case-control study. Blood 2000;96:23.

46. Dilawari JB, Bambery P, Chawla Y, et al. Hepatic outflow obstruction (Budd-Chiari syndrome). Experience with 177 patients and a review of the literature. Medicine 1994;73:21-36.

47. Rautou, P.E., Plessier, A., Bernuau, J. et al. Pregnancy: a risk factor for Budd-Chiari syndrome?. Gut 2009;58: 606-8.

48. Webb JA, Thomsen HS, Morcos SK. The use of iodinated and gadolinium contrast media during pregnancy and lactation. Eur Radiol 2005;15:1234-40.
49. Singh V, Sinha SK, Nain CK, et al. Budd-Chiari syndrome: our experience of 71 patients. J Gastroenterol Hepatol 2000;15:550-4.

50. Rautou PE, Angermayr B, Raffa S, et al. Maternal and foetal outcome in 27 women with Budd-Chiari syndrome (BCS) and 41 pregnancies. Hepatology 2007; 46:563.

51. Grant WJ, McCashland T, Botha JF, et al. Acute BuddChiari syndrome during pregnancy: surgical treatment and orthotopic liver transplantation with successful completion of the pregnancy. Liver Transpl 2003;9:976-9.

52. Denninger MH, Chait Y, Casadevall N, et al. Cause of portal or hepatic venous thrombosis in adults: the role of multiple concurrent factors. Hepatology 2000;31:587-91.

53. Janssen HL, Wijnhoud A, Haagsma EB, et al. Extrahepatic portal vein thrombosis: aetiology and determinants of survival. Gut 2001;49:720-4.

54. Primignani M, Martinelli I, Bucciarelli P, et al. Risk factors for thrombophilia in extrahepatic portal vein obstruction. Hepatology 2005;41:603-8.

55. Plessier A, Darwish-Murad S, Hernandez-Guerra M, et al. Acute portal vein thrombosis unrelated to cirrhosis: a prospective multicenter follow-up study. Hepatology 2010;51:210-8.

56. Borg MJ, Leemans WF, De Man RA, et al. Exacerbation of chronic hepatitis B infection after delivery. J Viral Hepatit 2008;15:37-41.

57. Office of Federal Register. Content and format of labeling for human prescription drug and biological products; requirements for pregnancy and lactation labeling; 2014. Available from: https://www.federalregister.gov/articles/2014/12/04/2014-28241/content

58. INC Research. The antiretroviral pregnancy registry interim report. INC Research, Wilmington, NC; 2013. Available from: http://www.apregistry.com/forms/interim_report.pdf Accessed: 18 January, 2015.

59. Wang L, Kourtis AP, Ellington S, et al. Safety of tenofovir during pregnancy for the mother and fetus: a systematic review. Clin Infect Dis 2013;57:1773-81.

60. Liu M, Cai H, Yi W. Safety of telbivudine treatment for chronic hepatitis B for the entire pregnancy. J Viral Hepatit 2013;20:65-70.

61. Xu WM, Cui YT, Wang L, et al. Lamivudine in late pregnancy to prevent perinatal transmission of hepatitis $B$ virus infection: a multicentre, randomized, doubleblind, placebo-controlled study. J Viral Hepatit 2009;16:94-103.

62. Pan CQ, Mi LJ, Bunchorntavakul C, et al. Tenofovir disoproxil fumarate for prevention of vertical transmission of hepatitis B virus infection by highly viremic pregnant women: a case series. Digest Dis Sci 2012; 57:2423-9.

63. Celen MK, Mert D, Ay M., et al. Efficacy and safety of tenofovir disoproxil fumarate in pregnancy for the prevention of vertical transmission of HBV infection. World J Gastroenterol 2013;19:9377-82.

64. Arshad M, El-Kamary SS, Jhaveri R. Hepatitis C virus infection during pregnancy and the newborn period - are they opportunities for treatment?. J Viral Hepatit 2011;18:229-36.

65. Garg V, van Heeswijk R, Yang Y, et al. The pharmacokinetic interaction between an oral contraceptive containing ethinylestradiol and norethindrone and the $\mathrm{HCV}$ 
protease inhibitor telaprevir. J Clin Pharmacol 2012; 52:1574-83.

66. Westbrook RH, Yeoman AD, Kriese S, et al. Outcomes of pregnancy in women with autoimmune hepatitis. J Autoimmun 2012;38:239-44.

67. Terrabuio DRB, Abrantes-Lemas CP, Carrilho FJ, et al. Follow-up of pregnant women with autoimmune hepatitis. J Clin Gastroenterol 2009;43:350-6.

68. Sato H, Tomita K, Yasue C, et al. Pregnant woman with non-comatose autoimmune acute liver failure in the second trimester rescued using medical therapy: a case report. Hepatol Res 2014;45:1-7.

69. Candia L, Marquez J, Espinoza LR. Autoimmune hepatitis and pregnancy: a rheumatologist's dilemma. Semin Arthritis Rheum 2005;35:49-56.

70. Lohse AW, Mieli-Vergani G. Autoimmune hepatitis. J Hepatol 2011;55:171-82.

71. Buchel E, Van Steenbergen W, Nevens F, et al. Improvement of autoimmune hepatitis during pregnancy followed by flare-up after delivery. Am J Gastroenterol 2002;97:3160-5.

72. Trivedi PJ, Kumagi T, Al-Harthy N, et al. Good maternal and foetal outcome for pregnant women with primary biliary cirrhosis. Clin Gastroenterol Hepatol 2014; 12:1179-85.

73. Floreani A, Infantolono C, Franceschet I, et al. Pregnancy and primary biliary cirrhosis: a case-control study. Clin Rev Allergy Immunol 2014 [Epub ahead of print].

74. Poupon R, Chrétien Y, Chazouillères O, et al. Pregnancy in women with ursodeoxycholic acid-treated primary biliary cirrhosis. J Hepatol 2005;42:418-9.

75. Vitek L, Zelenkova M, Bruha R. Safe use of ursodeoxycholic acid in breast-feeding patient with primary biliary cirrhosis. Digest Liver Dis 2010;42:911-2.

76. Schrumpf E, Boberg KM. Epidemiology of primary sclerosing cholangitis. Best practice and research. Clin Gastroenterol 2001;15:553-62.

77. Landon MB, Soloway RD, Freedman LJ, et al. Primary sclerosing cholangitis and pregnancy. Obstet Gynecol 1987;69:457-9.

78. European Association for the Study of the Liver. EASL clinical practice guidelines for HFE hemochromatosis. J Hepatol 2010;53:3-22.

79. Cauza E, Hanusch-Enserer U, Bischof M, et al. Increased $\mathrm{C} 282 \mathrm{Y}$ heterozygosity in gestational diabetes. Foetal Diagn Ther 2005;20:349-54.

80. European Association for the Study of the Liver. EASL clinical practice guidelines: Wilson's disease. J Hepatol 2012;56:671-85.

81. Malik A, Khawaja A, Sheikh L. Wilson's disease in pregnancy: case series and review of literature. BMC Res Notes 2013;6:421.

82. Ferrecchia IA, Guenette G, Potocik EA, et al. Pregnancy in women with glycogen storage disease Ia and Ib. J Perinat Neonat Nurs 2014;28:26-31.

83. Tan J, Surti B, Saab S. Pregnancy and cirrhosis. Liver Transpl 2008;14:1081-91.

84. Brunt PW, Kew MC, Scheuer PJ, et al. Studies in alcoholic liver disease in Britain. I. Clinical and pathological patterns related to natural history. Gut 1974;15:52-8.

85. Fesenmeier MF, Coppage KH, Lambers DS, et al. Acute fatty liver of pregnancy in 3 tertiary care centers. Am J Obstet Gynecol 2005;192:1416-9.
86. Jones KL, Smith DW. Recognition of the foetal alcohol syndrome in early infancy. Lancet 1973;2:999-1001.

87. Stokkeland K, Ebrahim F, Hultcrantz R, et al. Increased risks of epilepsy and neuropsychiatric diseases in children of mothers with alcoholic liver disease. Liver Int 2013;33:266-72.

88. Guerrini I, Jackson S, Keaney F. Pregnancy and alcohol misuse. Br Med J 2009;338:845.

89. Henderson J, Gray R, Brocklehurst P. Systematic review of effects of low-moderate prenatal alcohol exposure on pregnancy outcome. BJOG 2007;114:243-52.

90. Goldberg RL, Culhane JF, Iams JD, et al. Epidemiology and causes of preterm birth. Lancet 2008;371:75-84.

91. Albertsen K, Andersen A-MN, Grönbaeck M. Alcohol consumption during pregnancy and the risk of preterm delivery. Am J Epidemiol 2004;159:155-61.

92. Mullally A, Cleary BJ, Barry J, et al. Prevalence, predictors and perinatal outcomes of peri-conceptional alcohol exposure-retrospective cohort study in an urban obstetric population in Ireland. BMC Pregn Childb 2011;11:27.

93. Little RE, Anderson KW, Ervin CH, et al. Maternal alcohol use during breast-feeding and infant mental and motor development at one year. $\mathrm{N}$ Engl J Med 1989;321:425-30.

94. Heberlein A, Leggio L, Stichtenoth D, et al. The treatment of alcohol and opioid dependence in pregnant women. Curr Opin Psychiatr 2012;25:559-64.

95. Catalano PM. Obesity, insulin resistance and pregnancy outcome. Reprod 2010;140:365-71.

96. Buchanam T, Xiang AH. Gestational diabetes mellitus. J Clin Invest 2005;115:485-91.

97. Schaefer-Graf UM, Graf K, Kulbacka I, et al. Maternal lipids as strong determinants of foetal environment and growth in pregnancies with gestational diabetes mellitus. Diabetes Care 2008;31:1858-63.

98. Forbes S, Taylor-Robinson SD, Patel N, et al. Increased prevalence of non-alcoholic fatty liver disease in European women with a history of gestational diabetes. Diabetol 2011;54:641-7.

99. Heerwagen MJ, Miller MR, Barbour LA, et al. Maternal obesity and foetal metabolic programming: a fertile epigenetic soil. Am J Physiol 2010;299:R711-22.

100. Ruchat SM, Hivert MF, Bouchard L. Epigenetic programming of obesity and diabetes by in utero exposure to gestational diabetes mellitus. Nutr Rev 2013;71:S88-94.

101. Rautou PE, Angermayr B, Garcia-Pagan JC, et al. Pregnancy in women with known and treated Budd-Chiari syndrome: maternal and foetal outcomes. J Hepatol 2009;51:47-54.

102. Pajor A, Lehoczky D. Pregnancy and extrahepatic portal hypertension. Review and report on the management. Gynecol Obstet Invest 1990;30:193-7.

103. Starkel P, Horsmans Y, Geubel A. Endoscopic band ligation: a safe technique to control bleeding esophageal varices in pregnancy. Gastrointest Endosc 1998;48:212-4.

104. Benjaminov FS, Heathcote J. Liver disease in pregnancy. Am J Gastroenterol 2004;99:2479-88. 